Article

\title{
Species Detection within the Echinococcus granulosus sensu lato Complex by Novel Probe-Based Real-Time PCRs
}

\author{
Pavlo Maksimov ${ }^{1, *}$, Hannes Bergmann ${ }^{1}$, Marion Wassermann ${ }^{2}$, Thomas Romig ${ }^{2}$, \\ Bruno Gottstein ${ }^{3,+}\left(\mathbb{D}\right.$, Adriano Casulli ${ }^{4,5}$ (D) and Franz J. Conraths ${ }^{1}$
}

1 Friedrich-Loeffler-Institut, Federal Research Institute for Animal Health, Institute of Epidemiology, National Reference Centre for Echinococcosis, 17493 Greifswald-Insel Riems, Germany; Hannes.Bergmann@fli.de (H.B.); Franz.Conraths@fli.de (F.J.C.)

2 Parasitology Unit, University of Hohenheim, Emil-Wolff-Str. 34, 70599 Stuttgart, Germany; Marion.Wassermann@uni-hohenheim.de (M.W.); Thomas.Romig@uni-hohenheim.de (T.R.)

3 Institute of Parasitology, Vetsuisse Faculty and Faculty of Medicine, University of Bern, 3012 Bern, Switzerland; bruno.gottstein@vetsuisse.unibe.ch

4 WHO Collaborating Centre for the Epidemiology, Detection and Control of Cystic and Alveolar Echinococcosis, Department of Infectious Diseases, Istituto Superiore di Sanità, 00161 Rome, Italy; adriano.casulli@iss.it

5 European Reference Laboratory for Parasites, Department of Infectious Diseases, Istituto Superiore di Sanità, 00161 Rome, Italy

* Correspondence: pavlo.maksimov@fli.de

+ Present address: Institute of Infectious Diseases, Faculty of Medicine, University of Bern, 3012 Bern, Switzerland.

Received: 28 August 2020; Accepted: 23 September 2020; Published: 26 September 2020

\begin{abstract}
Infections with eggs of Echinococcus granulosus sensu lato (s.l.) can cause cystic echinococcosis in intermediate host animals and humans. Upon ingestion of viable eggs, oncospheres hatch from the eggs and subsequently develop into fluid-filled larval cysts, most frequently in the liver or the lungs. The slowly growing cysts progressively interfere with organ function. The risk of infection is determined by the host range of the parasite, its pathogenicity and other epidemiologically relevant parameters, which differ significantly among the five species within the E. granulosus s.l. complex. It is therefore essential to diagnose the correct species within E. granulosus s.l. to help understand specific disease epidemiology and to facilitate effective implementation of control measures. For this purpose, simple, fast and cost-effective typing techniques are needed. We developed quantitative real-time polymerase chain reactions (qPCRs) to target polymorphic regions in the mitochondrial genome of E. granulosus s.l. In a single-step typing approach, we distinguished E. granulosus s.l. members in four epidemiologically relevant subgroups. These were E. granulosus sensu stricto, E. equinus, E. ortleppi and the E. canadensis cluster. The technique also allowed identification and differentiation of these species from other Echinococcus or Taenia taxa for samples isolated from cysts or faeces.
\end{abstract}

Keywords: Echinococcus granulosus sensu lato species diagnosis; real-time polymerase chain reaction; DNA probe

\section{Introduction}

Infection with Echinococcus granulosus sensu lato (E. granulosus s.l.) [1] can cause cystic echinococcosis (CE) in animals and humans [2-5].

Previously, E. granulosus was considered to be a single species, subdivided into "strains" and genotypes (G1 to G8, G10 and the "lion strain") [4], most of them associated with specific 
definitive-intermediate hosts and geographic distribution patterns [6]. Currently, some of these taxa are considered distinct species within the E. granulosus s.l. complex, while others are retained as genotypes within some of these species. Thus, E. granulosus sensu stricto (s.s.) is composed of genotypes G1 and G3, while G2 is no longer considered a distinct genotype [7]. In addition, the G1-G3 cluster includes other closely related haplotypes, which-depending on the definition-may or may not belong to these genotypes. These are named Gx in this study. E. granulosus s.s. is mainly associated with sheep as its intermediate host and causes the largest number of human cases worldwide. Second, E. equinus (formerly genotype G4) is associated with horses and rarely, if ever, causes human disease. Third, E. ortleppi (formerly genotype G5), associated with cattle, seems to be of low pathogenicity to humans, while, fourth, E. canadensis (composed of genotypes G6, G7, G8 and G10) is mainly associated with cervids, camels, goats and pigs and causes the second largest number of human patients; it may have to be subdivided into two or more species and is best referred to as "E. canadensis-cluster". Lastly, E. felidis (formerly "lion strain") is a wildlife parasite from sub-Saharan Africa, which seems to be present only where lions still exist; no human cases have been reported so far. Apart from these five species, a yet unnamed taxon (G-Omo), related to, but not belonging to the G1-3 cluster of E. granulosus s.s., has been described from a human patient in southern Ethiopia [4,8-12].

Accurate identification and reporting to the species level within E. granulosus s.l. is critical to prevent or control parasite spread and further accidental ingestion by humans. With possible exception of E. felidis, all species/genotypes are zoonotic and can cause serious CE in humans, who act as aberrant, dead-end intermediate hosts. Identifying the individual species within E. granulosus s.l. is also necessary for a detailed epidemiological understanding of the disease in its geographic distribution, for surveillance purposes, and ultimately for implementing effective prevention and control measures. This is particularly important in endemic areas, where several Echinococcus species and other taeniid cestodes coexist. This differentiation is also important to assess the different zoonotic potential of the various species [13] in intermediate and aberrant hosts at risk [13,14]. According to a recent expert consensus, specific differentiation of the E. granulosus s.l. complex should be done with any kind of sample whenever technically feasible [1].

Methods used for the diagnosis of Echinococcus infections in definitive and intermediate hosts include classical parasitological techniques such as microscopic examination of intestinal scrapings, counting procedures and sedimentation and flotation of faecal samples [15-19] as well as molecular techniques such as polymerase chain reaction (PCR) which are particularly useful for species or genotype differentiation $[13,14]$. The traditional parasitological methods are important for the preparation and pre-selection of sample material, but generally do not provide sufficient acuity for species differentiation. Several PCR protocols for detection and differentiation of species within E. granulosus s.l. have been published [20-23]. However, most of these protocols are based on conventional PCR techniques and either require an additional sequencing step for unambiguous determination, or are limited to certain Echinococcus species, taxa or genotypes. Therefore, a tool for simultaneous testing for and typing of species within E. granulosus s.l. in a parallel manner would be a helpful addition to the diagnostic toolbox. Such a tool would enable reliable, simple, fast and affordable diagnosis to the species level (E. granulosus s.s., E. equinus, E. ortleppi [G5]) and E. canadensis).

Here we show that sequence-specific DNA probe-based quantitative PCR (qPCR) amplification of polymorphic target regions can be used as a single-step diagnostic tool for the differentiation of the four most important Echinococcus species that cause cystic echinococcosis. Diagnostic DNA probe qPCR tests were successfully applied, also together with an internal control in duplex or triplex format to identify the single species derived from cystic material or faecal matter. We anticipate that this tool will not only make diagnosis easier and faster, but will also be of use for epidemiological studies, effective prevention planning and control programs $[13,14]$. 


\section{Results}

\subsection{Primer Selection for the Amplification of E. granulosus s.l. Species Sequences}

To design PCR primers and TaqMan ${ }^{\circledR}$ PCR probes that allow diagnostic differentiation between the targeted species, mitochondrial genome sequences were bioinformatically analysed (Figure 1).

A
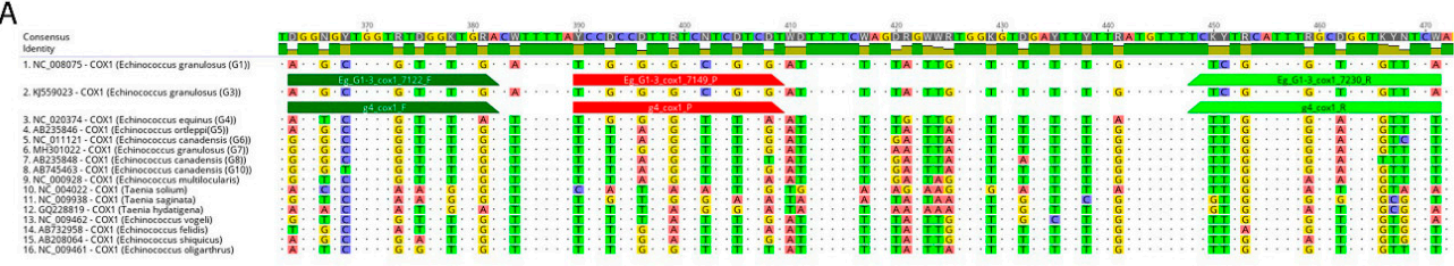

B
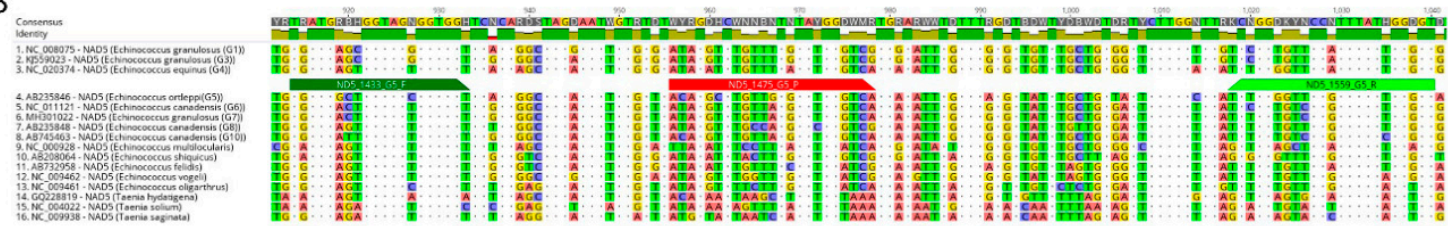

C
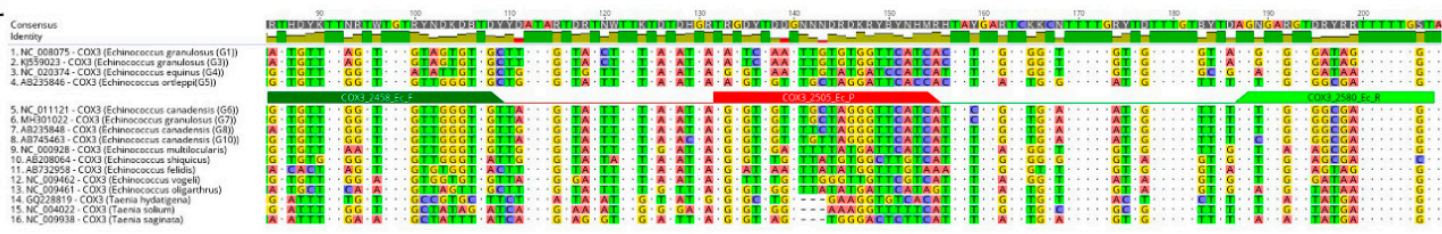

Figure 1. Location of Echinococcus granulosus sensu lato polymorphic genome regions within COX1, COX3 and NAD5 genes used for primer and probes design. In-silico identification of polymorphic regions in aligned mitochondrial DNA sequences to differentiate the E. granulosus sensu lato species E. granulosus sensu stricto (G1-3): (A), E. equinus (G4); (A), E. ortleppi (G5); (B) and E. canadensis (G6-8, G10); (C) from other Echinococcus spp. and Taenia spp. Differences between aligned sequences are highlighted by different background colours of respective nucleotides. Dots represent nucleotides identical in all aligned sequences. Dark-green bars show the positions of the respective forward primer, red bars annotate the positions of the respective probes, and light-green bars indicate the positions of the reverse primer. The name of each aligned sequence consists of NCBI nucleotide database accession number, followed by gene name and the name of Echinococcus species. G: genotype.

The mitochondrial genomes of species and intraspecific genotypes from the E. granulosus s. $l$. complex were screened for polymorphic regions that could be used as targets for specific PCR primer pairs and corresponding probes. Identified regions and verified primers and probes for all four species, E. granulosus s.s. (G1-G3), E. equinus (G4), E. ortleppi (G5), and E. canadensis (G6-10), are shown in Table 1 and Figure 1. 
Table 1. Identified primer and probe sequences for detection and typing of Echinococcus granulosus sensu lato species by TaqMan ${ }^{\circledR}$ quantitative real-time polymerase chain reaction (qPCR).

\begin{tabular}{|c|c|c|c|c|c|c|c|c|}
\hline Assay Name & Primer Name & Product Size & Specificity & Sequence & $\begin{array}{c}\text { Final } \\
\text { Concentration }\end{array}$ & Gene & Accession No & $\begin{array}{l}\text { Position in } \\
\text { Mitochondrial } \\
\text { Genome }\end{array}$ \\
\hline \multirow{3}{*}{ G1_3_qPCR } & Eg_G1-3_cox1_7122_F & \multirow{3}{*}{109} & \multirow{3}{*}{$\begin{array}{l}\text { E. granulosus } \\
\text { sensu stricto } \\
(\text { G1, G3) }\end{array}$} & AGGGGCTGGTGTTGGTTGGA & $200 \mathrm{nM}$ & \multirow{3}{*}{ Cox1 } & \multirow{3}{*}{$\begin{array}{c}\text { KJ559023, } \\
\text { NC_008075.1, } \\
\text { KJ162553 }\end{array}$} & $7122-7141$ \\
\hline & Eg_G1-3_cox1_7230_R & & & TGAAACACCAGCCAAATGCAGAGA & $200 \mathrm{nM}$ & & & $7230-7207$ \\
\hline & Eg_G1-3_cox1_7149_P & & & $\begin{array}{c}\text { 6-Fam or Cy5-TCC GCC GTT GTC CTC GTC } \\
\text { GT-BHQ-1 }\end{array}$ & $200 \mathrm{nM}$ & & & $7149-7168$ \\
\hline \multirow{3}{*}{ G4_qPCR } & g4_cox1_F & \multirow{3}{*}{109} & \multirow{3}{*}{ E. equinus (G4) } & AGG TGC TGG TGT TGG TTG AA & $200 \mathrm{nM}$ & \multirow{3}{*}{$\operatorname{Cox} 1$} & \multirow{3}{*}{ NC_020374 } & $9408-9427$ \\
\hline & g4_cox1_R & & & AGA AAC ACC TGC CAA ATG CAA AGA & $200 \mathrm{nM}$ & & & $9516-9493$ \\
\hline & g4_cox1_P & & & Сy3.5-TCC GCC GTT GTC TTC TTC AT-BMN-Q590 & $200 \mathrm{nM}$ & & & $9435-9454$ \\
\hline \multirow{3}{*}{ G5_qPCR } & ND5_1433_G5_F & \multirow{3}{*}{127} & \multirow{3}{*}{ E. ortleppi (G5) } & TGATGGCTGGTAGCGGTGGT & $200 \mathrm{nM}$ & \multirow{3}{*}{ Nad5 } & \multirow{3}{*}{ AB235846 } & $1433-1452$ \\
\hline & ND5_1475_G5_P & & & Cy5.5-ACAGGCCTGTTGTGTATGGGTCA-BMN-Q650 & $200 \mathrm{nM}$ & & & $1475-1497$ \\
\hline & ND5_1559_G5_R & & & ACCCCAATAAACGGAACCCCAGA & $200 \mathrm{nM}$ & & & $1559-1537$ \\
\hline \multirow{3}{*}{ G6_10_qPCR } & COX3_2458_Ec_F & \multirow{3}{*}{123} & \multirow{3}{*}{$\begin{array}{l}\text { E. canadensis } \\
(\mathrm{G} 6-8, \mathrm{G} 10)\end{array}$} & GTTGTTTTGGTTTGTGTTGGGTTGT & $200 \mathrm{nM}$ & \multirow{3}{*}{ Cox3 } & \multirow{3}{*}{$\begin{array}{l}\text { NC_011121.1 } \\
\text { MH301022 }\end{array}$} & $2458-2482$ \\
\hline & COX3_2505_Ec_P & & & $\begin{array}{c}\text { FAM or } \\
\text { Cy5-TGGGTTGTGTGCTAGGGTTCATCA-MGB }\end{array}$ & $200 \mathrm{nM}$ & & & $2505-2528$ \\
\hline & COX3_2580_Ec_R & & & ACCAAAAATCGCCACСТCACT & $200 \mathrm{nM}$ & & & $2580-2560$ \\
\hline \multirow{3}{*}{$\begin{array}{l}\text { Internal control } \\
\text { PCR, IC2 PCR }\end{array}$} & EGFP1-F & \multirow{3}{*}{$\begin{array}{l}\text { Hoffmann et al., } \\
2006\end{array}$} & \multirow{3}{*}{$\begin{array}{l}\text { Hoffmann et al., } \\
2006\end{array}$} & GAC CAC TAC CAG CAG AAC AC & $500 \mathrm{nM}$ & \multirow{3}{*}{ EGFP } & & \multirow{3}{*}{$\begin{array}{l}\text { Hoffmann et al., } \\
2006\end{array}$} \\
\hline & EGFP1 & & & $\begin{array}{c}5^{\prime} \text {-HEX- AGC ACC CAG TCC GCC CTG AGC A } \\
\text {-BHQ1 }\end{array}$ & $160 \mathrm{nM}$ & & & \\
\hline & EGFP2-R & & & GAA CTC CAG CAG GAC CAT G & $500 \mathrm{nM}$ & & & \\
\hline
\end{tabular}


We used reference samples of known tapeworm species and genotypes to test the newly identified primer pairs and probes. To ensure the identity of the reference material, tapeworm-specific DNA was amplified by conventional PCR and the resulting amplicons were then analysed by Sanger sequencing. The conventional PCR and sequencing results confirmed the identity of the DNA reference samples in all cases (Figure 2, sequencing results not shown).

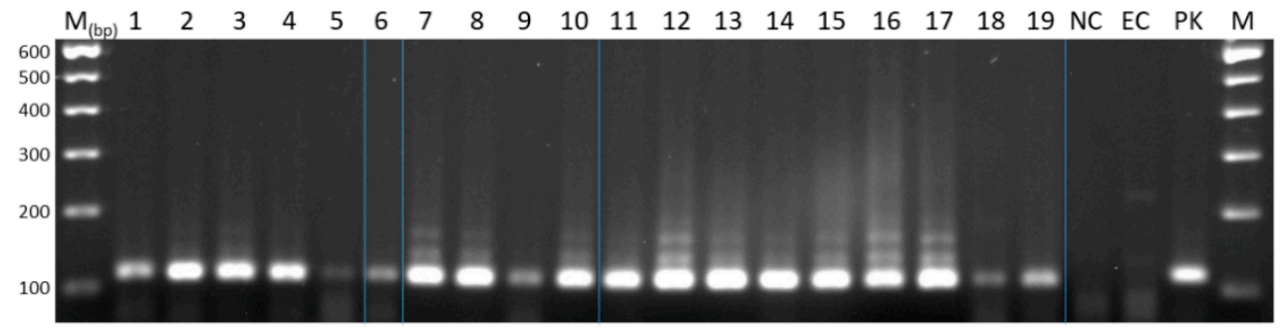

Figure 2. Reference DNA amplification of specific polymerase chain reaction (PCR) products of Echinococcus granulosus sensu lato. PCR products from reference DNAs obtained from Echinococcus granulosus sensu lato species amplified by specific PCR (Cest4, Cest5 (Trachsel et al., 2007)). 1: E. granulosus sensu stricto (G1), 2: E. granulosus s.s. (G3 ), 3: E. granulosus s.s. (G3), 4-5: E. granulosus s.s. (Gx), 6-7: E. equinus (G4), 8-10: E. ortleppi (G5), 11-12: E. canadensis (G6), 13: E. canadensis (G7), 14: E. canadensis (G8), 15-16: E. canadensis (G10), 17: E. vogeli, 18: E. felidis, 19: E. cf. granulosus (G-Omo). M: 100 base pair (bp) marker. NC: non-template control, EC: negative extraction control, PK: positive control. Blue vertical lines: gel spliced to clean up image and for labelling purposes.

The bioinformatically selected primer pairs were then examined by SYBR ${ }^{\circledR}$ green qPCR to test if they specifically amplified sequences from the genome of the targeted species. We found that the selected primer pairs for E. granulosus s.s. (G1-G3) and E. equinus (G4) specifically amplified their respective reference DNA and generated amplicons that were distinguishable by their melting peak temperatures from amplicons generated using samples with DNA from closely related Echinococcus spp. and Taenia spp. (Figure 3A,B). Furthermore, with the E. granulosus s.s. (G1-G3) primers, the melting temperature of $81{ }^{\circ} \mathrm{C}$ was distinguishable from the melting temperatures observed in amplicons generated with the same primer pair in reference samples of E. equinus (G4), E. ortleppi (G5) and E. canadensis (G6-10) at 79-80 ${ }^{\circ} \mathrm{C}$ (Figure 3A). The selected primer pair designed for E. equinus (G4) generated a specific PCR product and did not cross-react with samples of the other E. granulosus s.l. species or E. multilocularis (Figure 3B).

By contrast, primers designed to amplify sequences of E. ortleppi (G5), targeting a polymorphic sequence in Nad5, also yielded non-specific PCR products in the E. canadensis (G6-10) reference samples and vice versa, i.e., primers designed to generate E. canadensis (G6-10) amplicons from Cox3 also amplified E. ortleppi (G5) reference DNA. Whilst the selected primer pairs amplified PCR products in E. granulosus DNA samples, the resulting melting curves of all of the products were hardly distinguishable at the observed temperatures of 78 to $78.5^{\circ} \mathrm{C}$ for E. canadensis (G6-10) and $79{ }^{\circ} \mathrm{C}$ for E. ortleppi (G5) (Figure 3C,D). Nevertheless, the primers were selected for further testing in the TaqMan qPCR with their corresponding probes.

Additional primer and probe combinations that were initially selected in silico, but did not satisfactorily amplify sequences from the targeted species during SYBR ${ }^{\circledR}$ green, or in further TaqMan ${ }^{\circledR}$ qPCR experiments, are shown in the supplementary Table S1.

In summary, amplicon generating primer pairs were identified for all targeted species (Table 1). Conventional SYBR ${ }^{\circledR}$ green qPCR was sufficient to differentiate E. granulosus s. s. (G1-G3) and E. equinus (G4) using primers targeting polymorphic regions in Cox1 (Table 1) based on the generated amplicon alone. Using the same method, primers targeting regions in Nad5 in E. ortleppi (G5) and in Cox3 in E. canadensis (G6-8, G10) amplified successfully, but cross-reacted and required additional testing to separate the respective genotypes. 

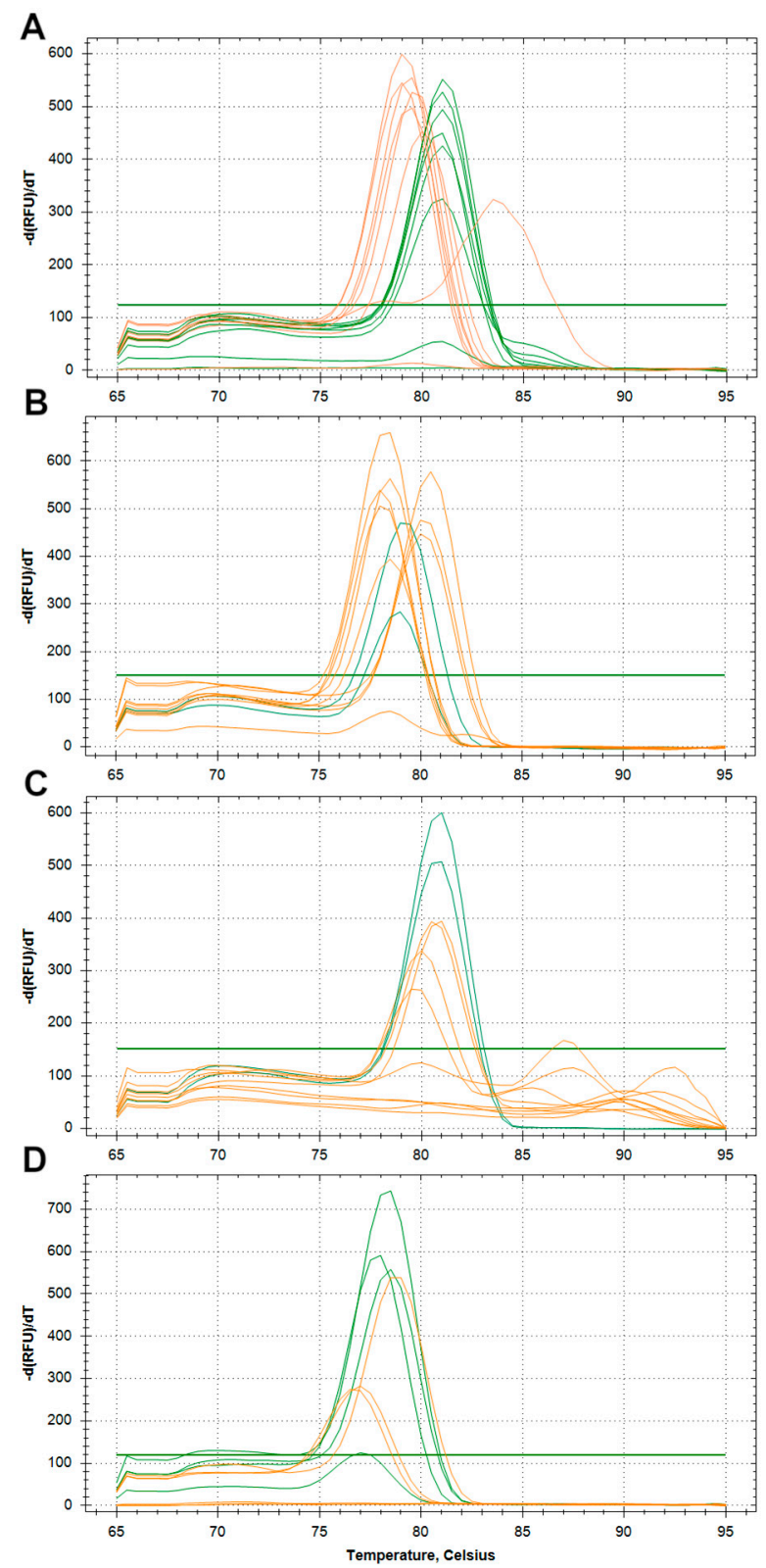

Figure 3. Quantitative SYBR ${ }^{\circledR}$ green PCR melting curves of Echinococcus reference DNA samples analysed with newly identified primer pairs. Green lines indicate peaks from targeted reference DNA. Orange lines indicate peaks from not-targeted reference DNAs. (A): Primer for detection of Echinococcus granulosus sensu stricto (G1-G3) DNA. (B): Primer for detection of E. equinus (G4) DNA. (C): Primer for detection of E. ortleppi (G5) DNA. (D): Primer for detection of E. canadensis (G6-8, G10) DNA.

\subsection{Detection of Echinococcus Species by TaqMan ${ }^{\circledR}$ Quantitative PCRs}

To increase the specificity of Echinococcus spp. target DNA detection, the four selected primer pairs were combined with amplicon-specific TaqMan ${ }^{\circledR}$ DNA probes (Table 1), and used to analyse serially diluted DNA reference samples (Figure 4). TaqMan ${ }^{\circledR}$ qPCR assays for E. granulosus s.s. (G1-G3) and E. equinus (G4) specifically identified target DNA in the corresponding reference samples. The selected probes for both subgroups did not bind DNA from the other E. granulosus s.l. species, from E. multilocularis spp. or from Taenia spp. (Table 2). Primers and probes for detecting E. granulosus s.s. (G1-G3) also amplified DNA from the $\mathrm{G}_{\mathrm{x}}$, strain sample, indicating that the assay is also applicable to other genotypes of E. granulosus s.s. 
A
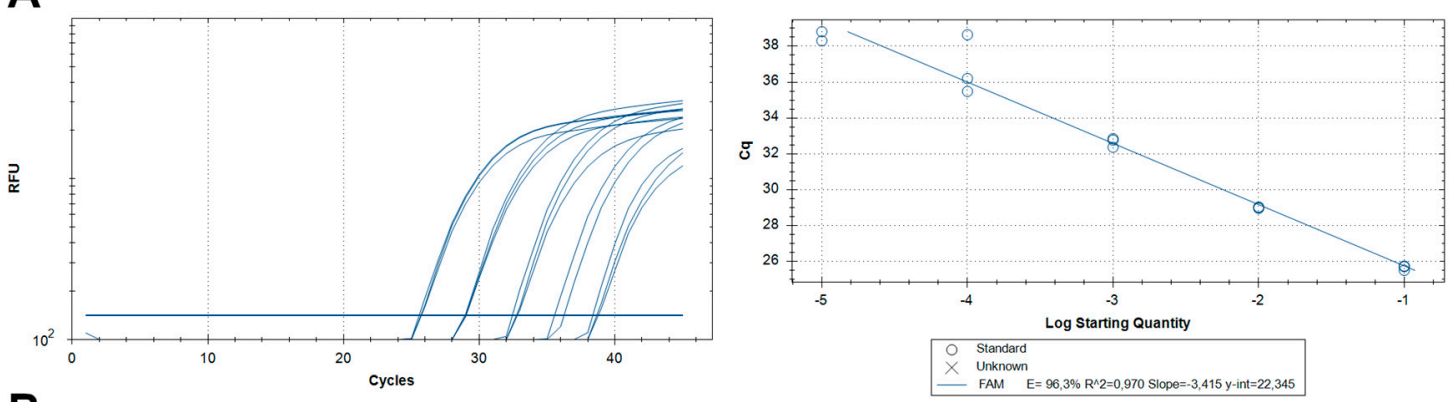

B
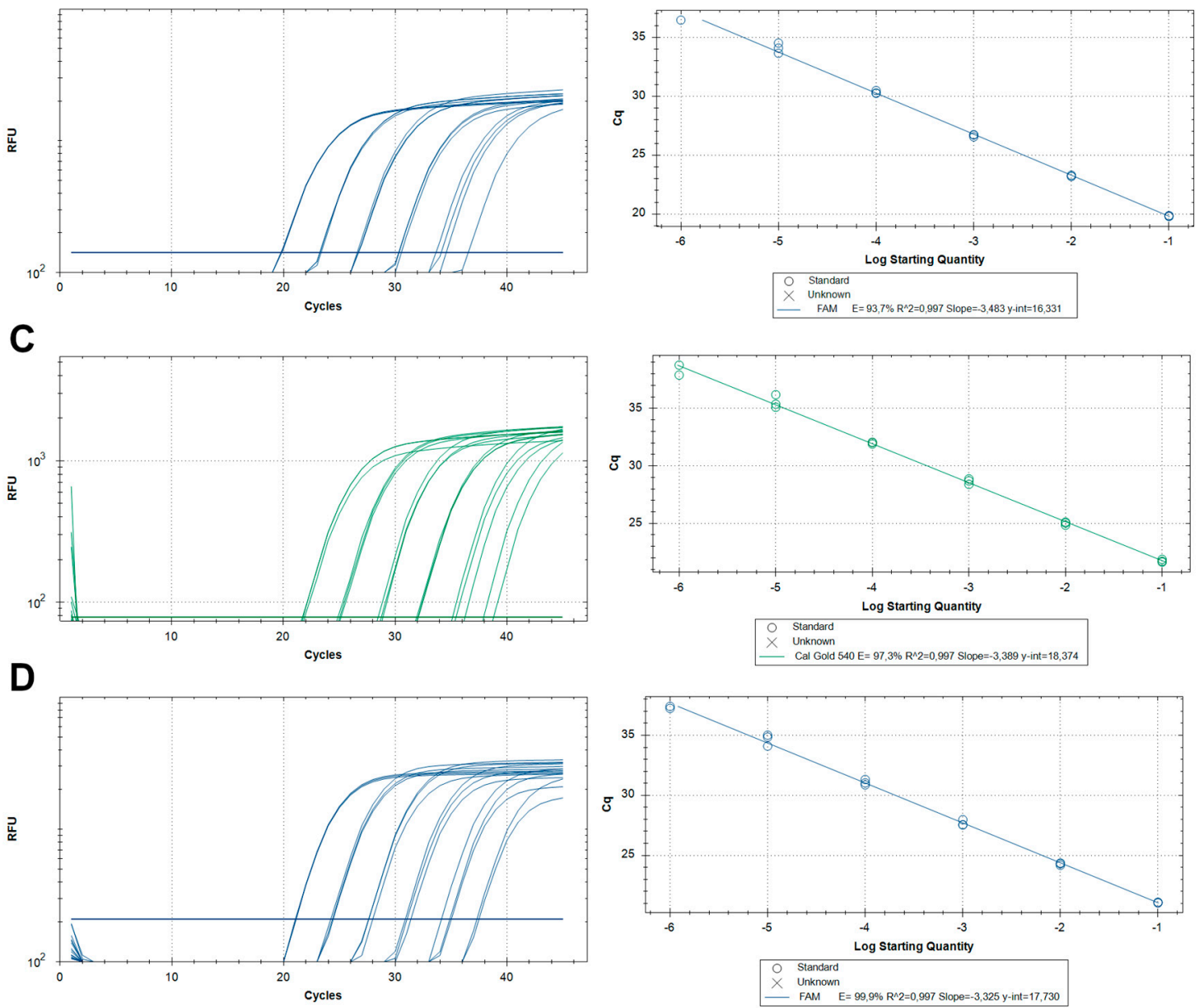

Figure 4. Fluorescence curves for developed TaqMan ${ }^{\circledR}$ qPCRs of serially diluted Echinococcus reference DNA samples. (A): G1_3_qPCR: E. granulosus s.s.,(B): G4_qPCR: E. equinus, (C): G5_10_qPCR: E. ortleppi, and (D): G5_10_qPCR: E. canadensis. RFU: relative fluorescence units. Cq: quantification cycle.

The addition of TaqMan ${ }^{\circledR}$ probes to qPCR reactions with selected G5_qPCR primer pairs for E. ortleppi (G5) also showed specific amplification of the DNA target region. No cross-reactions were recorded with DNA samples from the remaining Echinococcus spp. and Taenia spp. (Table 2). Thus, it appears that the addition of sequence-specific DNA probes ameliorated the cross-reactivity with the E. canadensis cluster observed in the qPCR system.

TaqMan ${ }^{\circledR}$ qPCR with the G6_G10_qPCR primer set targeting the E. canadensis $(G 6-8$, G10) cluster resulted in amplification of a probe-binding PCR product (Figure 4C,D). However, this assay also cross-reacted with the E. ortleppi (G5) DNA sample and thus did not allow differentiation of these two species (Table 2). To distinguish E canadensis (G6-8, G10) from G5 samples, we combined the G5_qPCR with the G6_G10_qPCR primer pairs and probes in a TaqMan ${ }^{\circledR}$ qPCR (G5_G10_qPCR) 
duplex format. With this format, DNA obtained from E. canadensis (G6-8, G10) is amplified only by a single fluorescence curve, which is specific for the E. canadensis (G6-8, G10). However, when the duplex qPCR amplifies an E. ortleppi (G5) DNA sample, both, the E. ortleppi (G5)-specific probe and the probe specific for E. canadensis (G6-8, G10) bind to the target region in the E. ortleppi (G5) DNA amplifying two fluorescence curves, as the primer and probe for E. canadensis (G6-8, G10) also amplified and detected E. ortleppi (G5) (Table 2). Therefore, the duplex TaqMan ${ }^{\circledR}$ qPCR format of G5_G10_qPCR primer and probes allowed diagnostic differentiation of E. ortleppi (G5) from the E. canadensis (G6-8, G10) cluster (Table 2).

Table 2. Specificity test results of TaqMan ${ }^{\circledR}$ qPCR assays.

\begin{tabular}{|c|c|c|c|c|c|}
\hline \multicolumn{2}{|c|}{ Reference DNA } & \multicolumn{4}{|c|}{ qPCR } \\
\hline Species & Genotype & G1_3_qPCR & G4_qPCR & G5_10_qPCR & G5_10_qPCR \\
\hline E. granulosus s.s. & G1 & 31.65 & $\mathrm{No} C q$ & $\mathrm{No} C q$ & No Cq \\
\hline E. granulosus s.s. & G3 & 28.53 & $\mathrm{No} C q$ & $\mathrm{No} C q$ & No Cq \\
\hline E. granulosus s.s. & G3 & 27.68 & No Cq & No Cq & $\mathrm{No} C q$ \\
\hline E. granulosus s.s. & Gx & 36.90 & No Cq & No Cq & No Cq \\
\hline E. granulosus s.s. & Gx & 37.46 & $\mathrm{No} C q$ & $\mathrm{No} C q$ & $\mathrm{No} C q$ \\
\hline E. equinus & G4 & $\mathrm{No} C q$ & 39.06 & $\mathrm{No} C q$ & $\mathrm{No} C q$ \\
\hline E. equinus & G4 & No Cq & 24.02 & No Cq & No Cq \\
\hline E. ortleppi & G5 & No Cq & $\mathrm{No} \mathrm{Cq}$ & 27.53 & 28.02 \\
\hline E. ortleppi & G5 & No Cq & $\mathrm{No} \mathrm{Cq}$ & 35.96 & 35.54 \\
\hline E. ortleppi & G5 & No Cq & No Cq & 26.02 & 26.54 \\
\hline E. canadensis & G6 & No Cq & No Cq & No Cq & 37.56 \\
\hline E. canadensis & G6 & No Cq & $\mathrm{No} C q$ & $\mathrm{No} C q$ & 28.37 \\
\hline E. canadensis & G7 & No Cq & No Cq & $\mathrm{No} \mathrm{Cq}$ & 25.57 \\
\hline E. canadensis & G8 & No Cq & No Cq & No Cq & 29.6 \\
\hline E. canadensis & G10 & No Cq & No Cq & No Cq & 27.11 \\
\hline E. canadensis & G10 & No Cq & No Cq & No Cq & 21.0 \\
\hline E. vogeli & & No Cq & No Cq & No Cq & No Cq \\
\hline E. felidis & & No Cq & No Cq & $\mathrm{No} C q$ & $\mathrm{No} C q$ \\
\hline E. cf. granulosus & G-Omo & No Cq & No Cq & No Cq & No Cq \\
\hline T. saginata & & No Cq & No Cq & No Cq & No Cq \\
\hline T. saginata & & No Cq & No Cq & No Cq & No Cq \\
\hline T. hydatigena & & No Cq & No Cq & No Cq & No Cq \\
\hline E. multilocularis & & No Cq & No Cq & $\mathrm{No}_{\mathrm{Cq}}$ & No Cq \\
\hline T. hydatigena & & No Cq & No $\mathrm{Cq}$ & No $\mathrm{Cq}$ & No Cq \\
\hline
\end{tabular}

To characterise the diagnostic TaqMan ${ }^{\circledR}$ qPCR assays further, the analytical efficiency and the limit of detection (LoD) of the qPCR reactions for each subgroup were determined by testing DNA extracted from clinical samples as cloned PCR products (plasmid DNA) (Table 3, Figures 4 and 5). 
Table 3. Analytical sensitivity and efficiency of developed TaqMan ${ }^{\circledR}$ qPCRs.

\begin{tabular}{|c|c|c|c|c|c|}
\hline PCR Name & Specificity & $\begin{array}{l}\text { Efficiency with } \\
\text { Cloned PCR } \\
\text { Products }\end{array}$ & $\begin{array}{c}\text { Efficiency Clinical } \\
\text { DNA }\end{array}$ & $\begin{array}{c}\text { Detection Limit } \\
\text { (Copy Number/ } \mu \mathrm{L} \text { at } \\
\text { Cq) with Cloned PCR } \\
\text { Products }\end{array}$ & $\begin{array}{c}\text { Detection } \\
\text { Limit in Cq } \\
\text { with Clinical } \\
\text { DNA }\end{array}$ \\
\hline $\begin{array}{l}\text { G1_3_qPCR } \\
\text { (single-plex) }\end{array}$ & $\begin{array}{c}\text { E. granulosus s.s. } \\
(\mathrm{G} 1, \mathrm{G} 3)\end{array}$ & $\begin{array}{c}100.7 \%\left(R^{2}=0.99\right. \\
\text { slope }=-3.34)\end{array}$ & $\begin{array}{c}96.3 \%\left(R^{2}=0.99\right. \\
\text { slope }=-3.41)\end{array}$ & $0.8 / \mu \mathrm{L}$ at $\mathrm{Cq} 36( \pm 0.9)$ & $38.24( \pm 0.1)$ \\
\hline $\begin{array}{l}\text { G4_qPCR } \\
\text { (single-plex) }\end{array}$ & E. equinus (G4) & $\begin{array}{c}106.7 \%\left(R^{2}=0.99\right. \\
\text { slope }=-3.32)\end{array}$ & $\begin{array}{c}93.7 \%\left(R^{2}=0.99\right. \\
\text { slope }=-3.48)\end{array}$ & $0.6 / \mu \mathrm{L}$ at $\mathrm{Cq} 39( \pm 0.6)$ & $38( \pm 1)$ \\
\hline $\begin{array}{l}\text { G5_G10_qPCR } \\
\text { (duplex) }\end{array}$ & E. ortleppi (G5) & $\begin{array}{c}100.7 \%\left(R^{2}=0.99\right. \\
\text { slope }=-3.34)\end{array}$ & $\begin{array}{c}97.3 \%\left(R^{2}=0.99\right. \\
\text { slope }=-3.39)\end{array}$ & $1.4 / \mu \mathrm{L}$ at $\mathrm{Cq} 36( \pm 0.7)$ & $37( \pm 0.4)$ \\
\hline $\begin{array}{l}\text { G5_G10_qPCR } \\
\text { (duplex) }\end{array}$ & $\begin{array}{l}\text { E. canadensis } \\
(\mathrm{G} 6-8, \mathrm{G} 10)\end{array}$ & $\begin{array}{c}101.6 \%\left(R^{2}=0.99\right. \\
\text { slope }=-3.28)\end{array}$ & $\begin{array}{c}99.9 \%\left(R^{2}=0.99\right. \\
\text { slope }=-3.33)\end{array}$ & $1.4 / \mu \mathrm{L}$ at $\mathrm{Cq} 36( \pm 0.8)$ & $38.6( \pm 0.17)$ \\
\hline
\end{tabular}

A

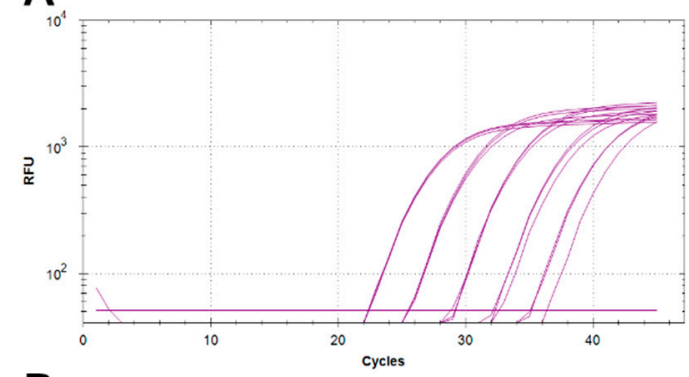

B

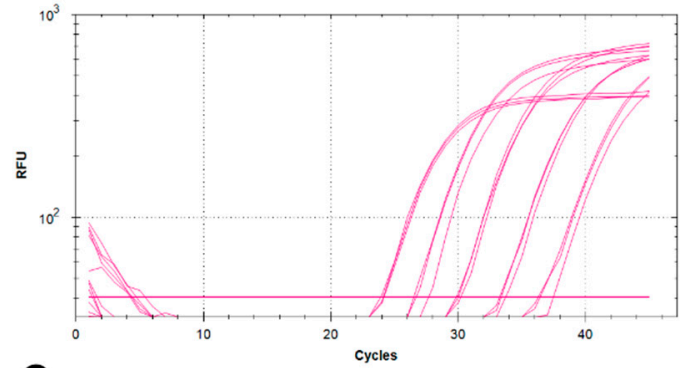

$\mathrm{C}_{10^{\circ}}$

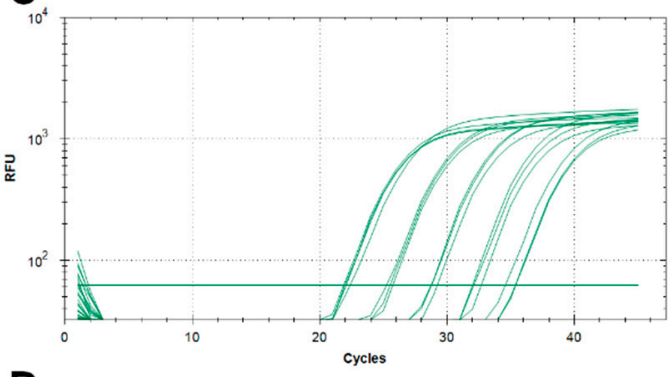

D

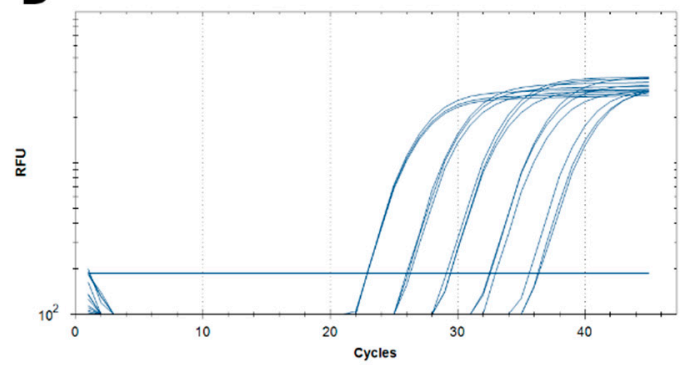

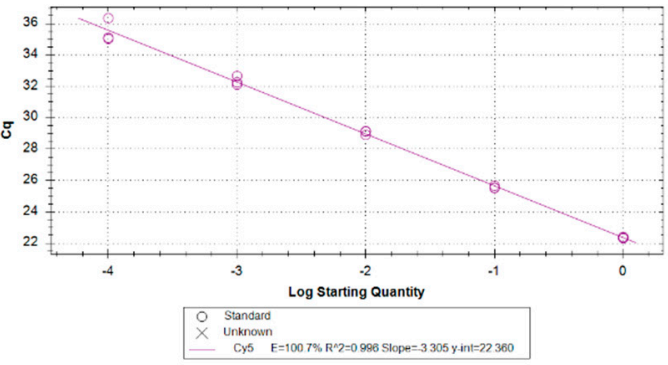
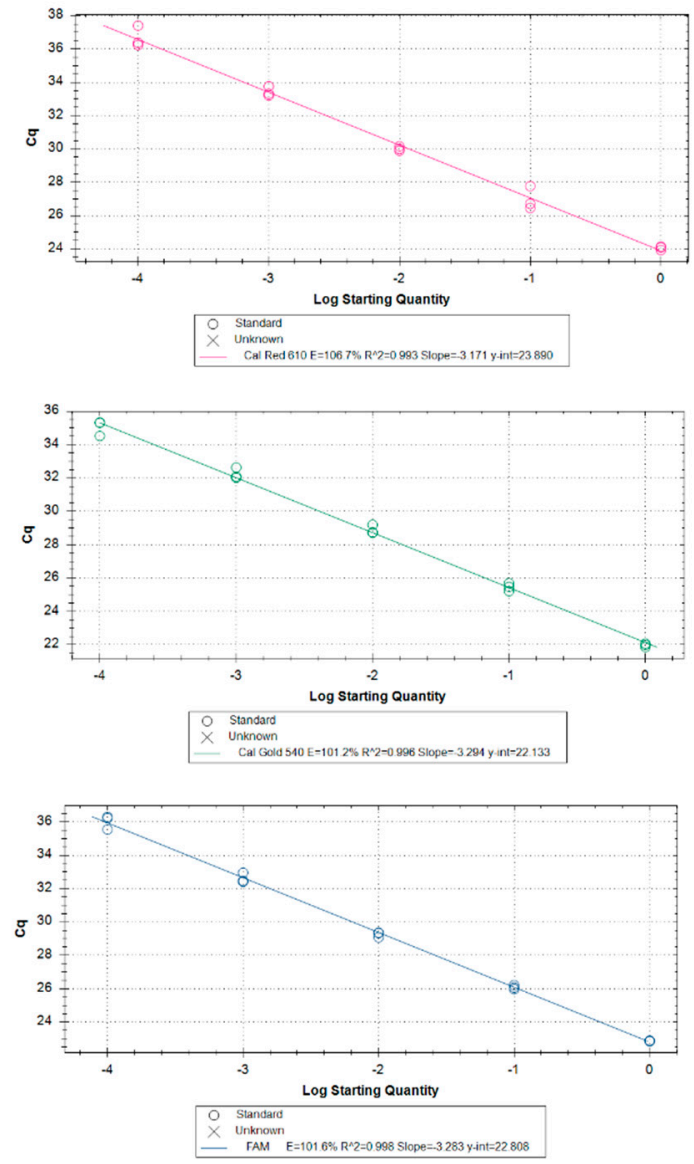

Figure 5. Fluorescence curves of serially diluted specific plasmid DNA samples analysed by TaqMan ${ }^{\circledR}$ qPCR. (A): G1_3_qPCR: E. granulosus s.s., (B): G4_qPCR: E. equinus, (C): G5_10_qPCR: E. ortleppi, and (D): G5_10_qPCR: E. canadensis. RFU: relative fluorescence units. Cq: quantification cycle. 
The analytical efficiency of TaqMan ${ }^{\circledR}$ qPCR assays varied between $94 \%$ and $107 \%$. The LoD of the assays varied between 0.6 and 1.4 copies/ $\mu \mathrm{L}$ (Table 3). The specificity in G1_3_qPCR, G4_qPCR and G5_qPCR was 100\%. G6_10_qPCR cross-reacted with E. ortleppi (G5) samples (Table 2) and required a duplex assay design with G5_qPCR for diagnostic purposes.

In summary, sequence-specific DNA probe-based TaqMan ${ }^{\circledR}$ qPCR assays were established that identified four species within E. granulosus s.l. in reference samples. These samples were further differentiated from other Echinococcus and Taenia species. (Table 2).

\subsection{Detection of E. granulosus s.l. Species in Faecal Samples}

The reference DNA samples used in this study for the development of qPCR assays that differentiate four Echinococcus species was derived from cyst wall material of metacestodes isolated from infected hosts. While cysts may serve as a sample matrix for the detection of E. granulosus s.l. species, it is diagnostically relevant that the assays also amplify target DNA extracted from other relevant matrices such as faecal matter. To test the performance of the TaqMan ${ }^{\circledR}$ qPCR assays when used with faecal samples, fox faeces were spiked with serially diluted reference DNA to simulate the testing of faeces from definitive hosts infected with members of E. granulosus s.l. A known quantity of standardised, heterologous plasmid DNA with matching primers and probes was included as an internal control (IC) in the qPCR mixture [24] to control for PCR inhibition by faecal factors. Inclusion of the IC also allowed testing the assays in duplex (G1_3_qPCR or G4_qPCR in combination with IC-qPCR) and triplex (G5_G10_qPCR and IC-qPCR) TaqMan ${ }^{\circledR}$ qPCR formats (see Table 1). All four assays targeting E. granulosus s.s. (G1-G3), E. equinus (G4), E. ortleppi (G5) and E. canadensis (G6-8, G10) respectively, amplified the specific tapeworm DNA region from each analysed faecal sample type (Table 4).

Table 4. Detection of E. granulosus s.l. species in faecal samples by duplex and triplex TaqMan ${ }^{\circledR}$ qPCRs.

\begin{tabular}{ccccccc}
\hline PCR Name & Specificity & $\mathbf{1 : 1 0 0}{ }^{\S}$ & $\mathbf{1 : 1 0 0}$ & $\mathbf{1 : 1 0 0 0}$ & $\mathbf{1 : 1 0 , 0 0 0}{ }^{*}$ & $\mathbf{1 : 1 0 0 , 0 0 0}^{*}$ \\
\hline G1_3_qPCR+IC_qPCR (duplex) & G1, G3 & 24.5 & $30.1( \pm 0.6)$ & $35.2( \pm 1)$ & neg. & neg. \\
\hline G4_qPCR+IC_qPCR (duplex) & G4 & 20.2 & $27.4( \pm 0.5)$ & $30.7( \pm 1)$ & $35.8( \pm 0.06)$ & neg. \\
\hline G5_10_qPCR+IC_qPCR (triplex) & G5 & 21,37 & $30.3( \pm 0.17)$ & $32.4( \pm 0.22)$ & neg. & neg. \\
\hline G5_10_qPCR+IC_qPCR (triplex) & G6-8, G10 & 24.2 & $31.2( \pm 0.02)$ & $32.6( \pm 0.22)$ & neg. & neg. \\
\hline $\begin{array}{l}\text { § Cq values from 1:100 pre-diluted DNA, extracted from cyst material. }{ }^{*} \text { Cq values from re-extracted DNA prepared } \\
\text { by logarithmic dilution of the corresponding DNA, used to spike faecal samples ( } \pm \text { standard deviation). }\end{array}$
\end{tabular}

Combining E. ortleppi, E. canadensis as well as IC primers and respective probes in a triplex qPCR differentiated E. ortleppi (G5) and E. canadensis (G6-8, G10) DNA in faecal samples (Table 4). Probe recognition of IC DNA and quantification showed that no inhibition of the amplification process had occurred in these faecal samples and that the selected primer probe mixtures performed reliably with samples prepared in a matrix of faecal matter under duplex or triplex qPCR conditions. The Cq values generated from the re-extracted tapeworm DNA from faeces were much higher than those from the non-faecal control samples i.e., DNA extracted from hydatid cyst material. This suggests that the quantities of re-extracted tapeworm DNA from faeces were much lower than from non-faecal control samples, possibly due to loss of DNA during the faecal DNA extraction process (Table 4).

Taken together, we developed four sequence-specific, DNA-probe-based qPCR assays that allow differentiation of E. granulosus s.l. species detected in DNA samples derived from cyst material or spiked faecal matter, namely E. granulosus s.s. (G1-G3), E. equinus (G4), E. ortleppi (G5) and E. canadensis (G6-8, G10).

\section{Discussion}

Cystic echinococcosis is a globally important parasitic zoonosis that requires well-informed prevention and control measures based on reliable and efficient diagnosis of the various causative agents [25,26]. 
By designing TaqMan ${ }^{\circledR}-\mathrm{qPCR}$ probes that directly identify polymorphic genome regions among the four most important species of the E. granulosus s.l. complex, we simplify and enhance current diagnostic procedures in multiple ways. The advantages include increased sensitivity, increased specificity, the ability to quantify sample DNA, reduced time-cost to achieve a diagnostic result and potentially reduced processing and equipment costs due to focusing on a single technology. Taken together, these methodological properties should significantly facilitate the process of establishing diagnostic capacities for the detection of E. granulosus s.l. in a field laboratory settings and also facilitate higher sample throughput for epidemiological studies [22,23].

We discriminate the individual CE agents diagnostically by targeting genetic variability of the mitochondrial genome. Using a bioinformatics approach, we first identified polymorphic regions in the genes Cox1, Cox3 and Nad5 (Figure 1), which have previously emerged as suitable targets for E. granulosus s.l. genotyping $[8,27]$. Selected primer-probe combinations for all but one species were specific, as the single-plex qPCR system for E. canadensis (G6-8, G10) cross-reacted with E. ortleppi (G5) samples (Table 2). One obvious possible explanation is the close relationship among these species, resulting in a low degree of polymorphism between E. ortleppi and E. canadensis in the Cox3 region targeted by G6-10 primers and probes. However, the non-specific G6-10-TaqMan ${ }^{\circledR}$ probe directed at Cox3 differed from its corresponding G5 sequence by four nucleotides ( $\mathrm{G}>\mathrm{A}, \mathrm{G}>\mathrm{A}, \mathrm{C}>\mathrm{T}$, $\mathrm{C}>\mathrm{T}$ ), whereas the specific G5-Nad5-probe differed only by three nucleotides when compared to its corresponding G6-10 sequence $(C>T, C>T, G>A$ ) (Figure 1). Therefore, it appears that nucleotide polymorphism alone is not sufficient to determine probe specificity in this context and that other single stranded DNA-affinity mechanisms, such as steric nucleotide relations [28], interact to overcome the mismatching probe-sequence in the G6-10 qPCR system. Furthermore, to avoid cross reactivity between G5 and E. canadensis complex (G6-10), we tested eight additional primers or primer/probe combinations derived from polymorphic regions of four mitochondrial genes, which unfortunately failed to eliminate this cross-reaction (Table S1). Our observations on this cross-reactivity are in accord with phylogenetic studies on the genome level that demonstrated a close relationship between E. ortleppi and E. canadensis [4,10]. Born from necessity, we therefore developed a duplex qPCR format, which now enabled successful G5 and G6-10 diagnosis for both samples in a single, parallel step.

Whilst phylogenetic relationships may contribute to diagnostic cross-reactivity, testing of E. granulosus s.s. haplotypes, which do not precisely fit with sequences of G1 and G3, but clearly belong to that species (here named Gx), showed that our assay correctly classified a "non-conventional" echinococcal isolate (Figure 2). Phylogenetic studies of E. granulosus s.s. isolates found that a large proportion of the identified haplotypes were not homologous with G1 and G3 in the classical sense of the G-nomenclature, yet they clearly belonged to the E. granulosus s.s. cluster $[4,10]$. Here, we classify the $G_{x}$-isolate that could not be assigned to the conventional G1-3 genotypes previously $[4,10]$ as E. granulosus s.s., which indicates a broad applicability of the G1_3_qPCR assay in the context of the natural genetic diversity in this subgroup (for an alternative interpretation of genotypes G1 and G3 see [7]).

The described qPCR system includes all species and genotypes of E. granulosus s.l. except E. felidis. However, this species, which is not known to be zoonotic, has a very fragmented distribution range in sub-Saharan Africa as it apparently depends on the presence of its principle definitive host, the lion. In any case, the genetic structure of African echinococcosis seems to be more complex than that found elsewhere and is in need of further research. This is illustrated by the presence of a highly divergent zoonotic genotype, G-Omo, in north-eastern Africa [27]. This genotype was only tentatively retained in E. granulosus s.s. pending further epidemiological information [27]. Interestingly, DNA of G-Omo did not react in the E. granulosus s.s. qPCR (as E. felidis, which belongs to the same species cluster), which supports a separate identity of this taxon. Likewise, E. canadensis may in future have to be split in two species, namely the wildlife-transmitted G8 and G10, and the largely domestically transmitted G6/7 genotype group [29]. This will not diminish the value of the qPCR, as both genotype clusters are 
allopatrically distributed and occur in very different epidemiological settings, with only a limited area of possible overlap in the Asian part of the Russian Federation [4].

The TaqMan ${ }^{\circledR}$-probe-based qPCR assays developed in this study show good efficiency, analytical specificity as well as diagnostic sensitivity when used with DNA obtained from cysts. Therefore, they are suitable for diagnosis of Echinococcus species in intermediate hosts, including humans and may be further validated in the field in different parts of the world under various conditions. Our findings in spiked faecal samples suggest that the duplex qPCR should also be applicable for the detection of E. granulosus s.l.-egg DNA in definitive hosts. Detection and genotyping of Echinococcus spp. DNA in faecal samples would be particularly useful when examining larger populations of living animals in the field for epidemiological studies. Whilst we characterised the LoD of the assays by using cloned amplicons (Table 3, Figures 4 and 5), their methodological and diagnostic sensitivity with faecal samples containing parasite eggs remains to be determined. A similar standardised, cloned-amplicon-based approach could be used to quantify target DNA in sample matrix of interest when using our assays. For instance, we observed an approx. 100-fold loss of specific DNA qPCR detection in spiked faecal samples (approx. 7 Cq-values) when compared to similar DNA quantities analysed in cyst material (Table 4). Inclusion of the IC-plasmid internal control suggested that the DNA loss occurred at the extraction step, as the amplification in faecal and non-faecal samples was comparable (Table 3). This observation further showed that faecal inhibitors known to potentially interfere with PCR amplification [30], had no noticeable effect in our qPCR system. However, faecal samples from other animals could harbour another combination of the inhibitory components, which may negatively influence the amplification process of the assays [30].

Due to the different designs of the experiments conducted to establish the already published PCRs, the assays are difficult to compare with TaqMan qPCRs described here concerning their diagnostic performance. Other sample matrices with different concentrations of target DNA, different materials, e.g., master mixes and PCR cyclers were applied.

We anticipate that single-step genotyping techniques for Echinococcus granulosus s.l. complex diagnosis by DNA-probe-based qPCR will complement the available methods, improve case reporting on the genotype level, advance our knowledge on the epidemiology of these parasites and ultimately support effective control of CE.

\section{Materials and Methods}

\subsection{Primer and DNA Probe Design for $q P C R s$}

For a bioinformatic prediction of suitable regions in the mitochondrial genome of Echinococcus spp., relevant sequences were downloaded from the public NCBI database. Accession numbers are listed in Table 1 and sequence analysis is summarised in Figure 1. Mitochondrial genomes were aligned using the "MAFFT" algorithm embedded in the Geneious Prime ${ }^{\circledR}$ (Version 2019.2.3) software suite. The program was used with default settings, whereby selection of the appropriate algorithm for the alignment was set to automatic. The Primer 3 algorithm, embedded in Geneious Prime ${ }^{\circledR}$, was then applied to all aligned sequences to predict potential targets for qPCR-based diagnosis. Thereafter, the in silico predicted qPCR targets were further analysed to find suitable polymorphic regions that might allow differentiating E. granulosus s.l. species of interest from others within the E. granulosus s.l. complex. To validate selected primer sequences in vitro, their performance was assessed in a SYBR ${ }^{\circledR}$ Green qPCR assay as described below.

\subsection{Reference DNA Samples and Faecal Spiking}

To develop and validate the qPCR, we utilised a panel of reference DNA samples from members of the E. granulosus s.l. complex and related cestode species as outgroup controls. We included E. granulosus s.s. (G1-3), E. equinus (G4), E. ortleppi (G5) and genotypes of the E. canadensis cluster (G6, G7, G8 and G10) (Table 5). 
Table 5. Reference DNA sample characteristics.

\begin{tabular}{|c|c|c|c|}
\hline Species & Genotype & Animal Origin & Geographical Origin \\
\hline E. granulosus s.s. & G1 & Cattle & Armenia \\
\hline E. granulosus s.s. & G3 & Sheep & Armenia \\
\hline E. granulosus s.s. & G3 & Sheep & France \\
\hline E. granulosus s.s. & Gx & Cattle & Armenia \\
\hline E. granulosus s.s. & Gx & Schaf & Ethiopia \\
\hline E. equinus & G4 & Zebra & Namibia \\
\hline E. equinus & G4 & NA & NA \\
\hline E. ortleppi & G5 & NA & NA \\
\hline E. ortleppi & G5 & Cattle & Kenya \\
\hline E. ortleppi & G5 & Cattle & Zambia \\
\hline E. canadensis & G6 & Camel & Kenya \\
\hline E. canadensis & G6 & Camel & Kenya \\
\hline E. canadensis & G7 & NA & NA \\
\hline E. canadensis & G8 & NA & Russia \\
\hline E. canadensis & G10 & NA & NA \\
\hline E. canadensis & G10 & Deer (Cervus sp.) & Russia \\
\hline E. vogeli & & NA & NA \\
\hline E. felidis & & Warthog & Namibia \\
\hline E. cf. granulosus & G-Omo & Human & Ethiopia \\
\hline T. saginata & & Cattle & Ethiopia \\
\hline T. hydatigena & & Dog & Ethiopia \\
\hline E. multilocularis & & Red fox & Germany \\
\hline
\end{tabular}

To verify the identity of the taxa in the reference material, we genotyped all DNA samples by conventional PCR (Figure 2) as described in this manuscript and shipped the obtained amplicons to Eurofins Genomics (Ebersberg, Germany) for Sanger sequencing. To minimise the cross-contamination risk among reference samples, the DNA quantity was reduced by diluting samples 1:100. These dilutions were used as working samples in all experiments. To determine the limit of detection (LoD) and the analytical efficiency of the TaqMan ${ }^{\circledR}$ qPCR assays, DNA samples were further diluted in ten-fold steps up to 1:10 ${ }^{-7}$ in Tris-EDTA buffer with $2 \mu \mathrm{g} / \mu \mathrm{L}$ Bovine Serum Albumin (BSA) (Carl Roth, Karlsruhe, Germany) [31]. As faecal matter is known to contain PCR inhibitory components [30], spiked faecal samples from a confirmed E. multilocularis-, and E. granulosus s.l.-free red fox (Vulpes vulpes) were prepared. To test whether E. granulosus s.l. species could be differentiated in DNA samples extracted from faecal samples, $200 \mathrm{mg}$ of faeces was spiked with reference DNA that had been serially diluted in ten-fold steps up to $1: 10^{-4}$. Each sample was prepared in duplicate. Spiked faecal samples were then processed using the ZR Faecal DNA MiniPrep ${ }^{\mathrm{TM}}$ kit (Zymo Research, Freiburg, Germany) to carry out DNA extraction as recommended in the kit manual.

\subsection{Conventional PCR}

To confirm the identity of the respective Echinococcus spp. in reference DNA samples, conventional PCR was performed as described elsewhere [20,30]. In brief, the following primers were used to amplify E. multilocularis DNA sequences (H15 F [5-CCATATTACAACAATATTCCTATC-3], 
EM-H17 R [5-GTGAGTGATTCTTGTTAGGGGAAG-3]), E. granulosus s.l. DNA (Cest4 F[5-GTT TTTGTGT GTTACATTAATAAGGGTG-3], Cest5 R[5-GCGGTGTGTACMTGAGCTAAAC-3]) and Taenia spp. DNA (Cest3 F[5-YGAYTCTTTTTAGGGGAAGGTGTG-3], Cest5 R[5-GCGGTGTGTAC MTGAGCTAAAC-3]) [20,32]. PCR was performed in a total volume of $25 \mu \mathrm{L}$ per sample with $2.5 \mu \mathrm{L}$ $10 \times$ PCR Rxn Buffer (Invitrogen Platinum ${ }^{\circledR}$ Taq Polymerase, Invitrogen GmbH, Darmstadt, Germany), $100 \mathrm{pmol} / \mu \mathrm{L}$ of each primer (synthesised at Eurofins Genomics, Ebersberg, Germany), $12.5 \mathrm{mM}$ dNTPs, $50 \mathrm{mM} \mathrm{MgCl} 2$ (InvitrogenPlatinum ${ }^{\circledR}$ Taq Polymerase), $5 \mathrm{U} / \mu \mathrm{L}$ Taq Polymerase (Invitrogen Platinum ${ }^{\circledR}$ Taq Polymerase, Qty. 300 Rxn) and $2.5 \mu \mathrm{L}$ DNA template. The PCR was performed in a Bio-Rad C1000 Thermal Cycler Detection System (Hercules, Bio-Rad Laboratories GmbH, Munich, Germany) applying the following cycle: $94{ }^{\circ} \mathrm{C}$ for $3 \mathrm{~min}$, thereafter 40 cycles with $94{ }^{\circ} \mathrm{C}$ for $30 \mathrm{~s}, 55^{\circ} \mathrm{C}$ for $30 \mathrm{~s}$ and $72{ }^{\circ} \mathrm{C}$ for $60 \mathrm{~s}$. PCR products were separated by agarose gel electrophoresis in $2 \%$ gels (Biozym ${ }^{\circledR}$ LEAgarose, Hessisch Oldendorf, Germany) with $0.2 \%$ ethidium bromide.

\subsection{Generic Quantitative PCR (SYBR ${ }^{\circledR}$ Green)}

To test the specificity of in silico selected primers, a generic quantitative PCR was carried out with a panel of reference DNAs. Primer and probes were obtained from Metabion (Planegg, Germany) (Table 5). The SYBR ${ }^{\circledR}$ Green qPCR was performed in a total volume of $20 \mu \mathrm{L}$. For the PCR reaction mixture, $10 \mu \mathrm{L}$ SsoAdvanced universal SYBR ${ }^{\circledR}$ Green supermix $(2 \times)$ (Biorad Laboratories GmbH, Munich, Germany), 10 pmol of each primer (forward and reverse), ultrapure nuclease-free water (Sigma-Aldrich, St. Louis, MO, USA) and $5 \mu \mathrm{L}$ of template DNA were used. The cycling conditions in the SYBR ${ }^{\circledR}$ Green real-time PCR were $98.0^{\circ} \mathrm{C}$ ( $3 \mathrm{~min}$, activating of Taq polymerase), followed by 40 cycles at $95.0^{\circ} \mathrm{C}$ for $15 \mathrm{~s}$ and at $60.0^{\circ} \mathrm{C}$ for $30 \mathrm{~s}$. After each cycle, the light emitted by the fluorophore was measured. The melting curve was constructed from 65 to $95^{\circ} \mathrm{C}$ at $0.5-^{\circ} \mathrm{C}$ increments with a dwell time of $5 \mathrm{~s}$ at each temperature. Real-time PCR results were analysed using the CFX Maestro software suite (Version: 3.1.15; Biorad Laboratories GmbH, Munich, Germany).

\subsection{Sequence-Specific DNA Probe Based Quantitative PCR (TaqMan $\left.{ }^{\circledR}\right)$ and Internal Control}

TaqMan ${ }^{\circledR}$ qPCR was performed as previously described [30,33]. In brief, the total reaction volume of $25 \mu \mathrm{L}$ per sample included $12.5 \mu \mathrm{L}$ TaqMan ${ }^{\circledR}$ qPCR master mix (QuantiTect ${ }^{\circledR}$ Multiplex PCR NoROX Kit (QIAGEN, Hilden, Germany), $1.25 \mu \mathrm{L}$ of the respective primer/probe mix (Table 2) (200 nM of each primer (forward and reverse) together with $200 \mathrm{nM}$ hydrolysis probe), $6.25 \mu \mathrm{L}$ ultrapure nuclease-free water (Sigma-Aldrich, St. Louis, MO, USA) and $5 \mu \mathrm{L}$ DNA template. Primers and probes were obtained from Eurofins Genomics (Ebersberg, Germany). The qPCR was carried out in a Bio-Rad CFX 96 Real-Time Detection System (Hercules, Bio-Rad Laboratories $\mathrm{GmbH}$, Munich, Germany) using the following thermal profile: $50^{\circ} \mathrm{C}$ for $2 \mathrm{~min}$, an initial denaturation step at $95^{\circ} \mathrm{C}$ for $15 \mathrm{~min}$ and 45 amplification cycles of $94{ }^{\circ} \mathrm{C}$ for $60 \mathrm{~s}$ followed by annealing and elongation at $59^{\circ} \mathrm{C}$ for $1 \mathrm{~min}$. When the reference DNA-spiked faecal samples were analysed by TaqMan ${ }^{\circledR}$ qPCR, a known quantity of heterologous plasmid DNA containing the enhanced green fluorescent protein (EGFP) gene [24] was included as an internal control (IC) in the qPCR mixture to detect potential inhibition. IC plasmids were added to each TaqMan ${ }^{\circledR}$ qPCR reaction mix along with the primers EGFP1-F, EGFP1-R and the probe EGFP1 (Table 5). The amount of the IC DNA added to each reaction was adjusted to result in a Cq value of about 30 in the respective qPCR tests. Each sample was tested by adding $12.5 \mu \mathrm{L}$ QuantiTect ${ }^{\circledR}$ Multiplex PCR NoROX Kit $(200 \times 50 \mu \mathrm{L}$ reactions, QIAGEN, Hilden, Germany), $1 \mu \mathrm{L}$ IC-DNA, $1.25 \mu \mathrm{L}$ of the respective primer/probe mix to detect Echinococcus spp. DNA, $0.3 \mu \mathrm{L}$ EGFP primer/probe mix and $4.95 \mu \mathrm{L}$ ultrapure nuclease-free water (Sigma-Aldrich, Missouri, USA). Due to a cross-reaction of the G6_10_qPCR primers with E. ortleppi (G5) DNA, this qPCR reaction had to be modified into a duplex format by combining it with G5_qPCR primers and probe. This duplex assay was further combined with the EGFP-PCR in a triplex format to test DNA samples extracted from faecal samples. The concentrations of the corresponding primers and probes are shown in Table 5 . Reactions were run in a total volume of $25 \mu \mathrm{L}$, which included $5 \mu \mathrm{L}$ template DNA extracted from 
faecal samples. The duplex and triplex TaqMan ${ }^{\circledR}$ qPCRs were also carried out in the Bio-Rad CFX 96 Real-Time Detection System (Hercules, Bio-Rad Laboratories GmbH, Munich, Germany), using the same thermal program as described above. Emitted fluorescence was measured at the end of every cycle. A negative extraction control that had been used in parallel throughout the DNA extraction process, a negative PCR control sample (sterile deionised water) and a positive control were included in all qPCR runs. LoD and analytical efficiency of the respective TaqMan ${ }^{\circledR}$ qPCRs were determined as described [34]. To this end, all samples were tested in triplicate and the PCR data were analysed using the Bio-Rad CFX Maestro 1.1 software package (version 4.12433.1219).

\subsection{Sequencing of $q P C R$ Products}

To verify qPCR amplicon sequences, purified amplicons from each single-plex TaqMan ${ }^{\circledR}$ qPCR were cloned into a plasmid vector using the PGEM $^{\circledR}$-T Easy Vector System I kit (Cat.\# A1360, Promega, Walldorf, Germany) and One Shot ${ }^{\circledR}$ TOP10 (Thermo Fisher Scientific, Waltham, MA, USA)) chemically competent Escherichia coli according to the manufacturer's instructions. Each plasmid vector DNA was then extracted from cultivated E. coli with the QIAprep Spin Miniprep Kit (QIAGEN, Hilden, Germany) according to the manufacturer's instructions and subsequently sequenced using the BigDye Terminator v1.1 Cycle Sequencing Kit and an ABI 3130 capillary sequencer (Thermo Fisher Scientific, Langenselbold, Germany). Sequences were aligned and assembled with the Geneious Prime ${ }^{\circledR}$ (2019.2.3) software package. The concentration of plasmid DNA containing the respective qPCR-specific products was determined by the Nanodrop technology (Thermo Fisher Scientific, Waltham, MA, USA)). The plasmid DNA copy number was estimated using an online tool (Plasmid DNA copy calculator [35]).

Supplementary Materials: The following are available online at http://www.mdpi.com/2076-0817/9/10/791/s1, Table S1: Non-successful primers and probes designed for E. granulosus s.l. species detection based on polymorphic mitochondrial genome regions.

Author Contributions: P.M., F.J.C. conceived and carried out the study. P.M. performed analysis of the data. P.M., F.J.C., H.B., M.W., T.R., B.G. and A.C. were involved in the design of the study and drafting of the manuscript. M.W., T.R., B.G. and A.C. provided DNA material. All authors read and approved the final manuscript.

Funding: This work was supported by funding from the European Union's Horizon 2020 Research and Innovation programme under grant agreement number 773830: One Health European Joint Programme (MEME project; https://onehealthejp.eu/jrp-meme/).

Acknowledgments: We would like to thank Alrik-Markis Kunisch and Susanne Zahnow for technical assistance. We also thank Bernd Hoffmann for discussions on the study design and Johanna Dups-Bergmann for critical reading of this manuscript. Furthermore, we would like to thank Hasmik Gevorgian for providing E. granulosus s.s. cyst material from Armenia, Yitagele Terefe for providing E. granulosus s.s. (Gx), T. saginata and T. hydatigena cyst material from Ethiopia, Ortwin Aschenborn for providing E. equinus (G4) cyst material from Namibia, Cecilia Mbae for providing E. ortleppi (G5) and E. canadensis (G6) from Kenya, Fredrick Banda for providing of E. ortleppi (G5) cyst material from Zambia, Sergey Konyaev for providing of E. canadensis (G8) cyst material from Russia, Liudmila Kokolova for providing of E. canadensis (G10) from Russia and Daniel Woldeyes for providing of E. canadensis (G8) cyst material from $E$. cf. granulosus $\left(G_{o m o}\right)$ from Ethiopia.

Conflicts of Interest: The authors declare no conflict of interest.

\section{References}

1. Vuitton, D.A.; McManus, D.P.; Rogan, M.T.; Romig, T.; Gottstein, B.; Naidich, A.; Tuxun, T.; Wen, H.; Menezes da Silva, A. World Association of Echinococcosis International consensus on terminology to be used in the field of echinococcoses. Parasite 2020, 27, 41. [CrossRef] [PubMed]

2. Kern, P.; Ammon, A.; Kron, M.; Sinn, G.; Sander, S.; Petersen, L.R.; Gaus, W.; Kern, P. Risk factors for alveolar echinococcosis in humans. Emerg. Infect. Dis. 2004, 10, 2088-2093. [CrossRef] [PubMed]

3. Bristow, B.N.; Lee, S.; Shafir, S.; Sorvillo, F. Human echinococcosis mortality in the United States, 1990-2007. PLoS Negl. Trop. Dis. 2012, 6, e1524. [CrossRef] [PubMed]

4. Romig, T.; Ebi, D.; Wassermann, M. Taxonomy and molecular epidemiology of Echinococcus granulosus sensu lato. Vet. Parasitol 2015, 213, 76-84. [CrossRef] [PubMed] 
5. Tappe, D.; Stich, A.; Frosch, M. Emergence of polycystic neotropical echinococcosis. Emerg. Infect. Dis. 2008, 14, 292-297. [CrossRef]

6. Romig, T.; Deplazes, P.; Jenkins, D.; Giraudoux, P.; Massolo, A.; Craig, P.S.; Wassermann, M.; Takahashi, K.; de la Rue, M. Ecology and Life Cycle Patterns of Echinococcus Species. Adv. Parasitol. 2017, 95, $213-314$. [CrossRef] [PubMed]

7. Kinkar, L.; Laurimae, T.; Sharbatkhori, M.; Mirhendi, H.; Kia, E.B.; Ponce-Gordo, F.; Andresiuk, V.; Simsek, S.; Lavikainen, A.; Irshadullah, M.; et al. New mitogenome and nuclear evidence on the phylogeny and taxonomy of the highly zoonotic tapeworm Echinococcus granulosus sensu stricto. Infect Genet Evol. 2017, 52, 52-58. [CrossRef]

8. Addy, F.; Wassermann, M.; Kagendo, D.; Ebi, D.; Zeyhle, E.; Elmahdi, I.E.; Umhang, G.; Casulli, A.; Harandi, M.F.; Aschenborn, O.; et al. Genetic differentiation of the G6/7 cluster of Echinococcus canadensis based on mitochondrial marker genes. Int. J. Parasitol. 2017, 47, 923-931. [CrossRef]

9. Wassermann, M.; Aschenborn, O.; Aschenborn, J.; Mackenstedt, U.; Romig, T. A sylvatic lifecycle of Echinococcus equinus in the Etosha National Park, Namibia. Int. J. Parasitol. Parasites Wildl. 2015, 4, 97-103. [CrossRef]

10. Nakao, M.; Lavikainen, A.; Yanagida, T.; Ito, A. Phylogenetic systematics of the genus Echinococcus (Cestoda: Taeniidae). Int. J. Parasitol. 2013, 43, 1017-1029. [CrossRef]

11. Nakao, M.; Yanagida, T.; Konyaev, S.; Lavikainen, A.; Odnokurtsev, V.A.; Zaikov, V.A.; Ito, A. Mitochondrial phylogeny of the genus Echinococcus (Cestoda: Taeniidae) with emphasis on relationships among Echinococcus canadensis genotypes. Parasitology 2013, 140, 1625-1636. [CrossRef] [PubMed]

12. Nakao, M.; Yanagida, T.; Okamoto, M.; Knapp, J.; Nkouawa, A.; Sako, Y.; Ito, A. State-of-the-art Echinococcus and Taenia: Phylogenetic taxonomy of human-pathogenic tapeworms and its application to molecular diagnosis. Infect. Genet. Evol. 2010, 10, 444-452. [CrossRef]

13. Craig, P.; Mastin, A.; van Kesteren, F.; Boufana, B. Echinococcus granulosus: Epidemiology and state-of-the-art of diagnostics in animals. Vet. Parasitol 2015, 213, 132-148. [CrossRef] [PubMed]

14. Siles-Lucas, M.; Casulli, A.; Conraths, F.J.; Muller, N. Laboratory Diagnosis of Echinococcus spp. in Human Patients and Infected Animals. Adv. Parasitol. 2017, 96, 159-257. [CrossRef]

15. Tackmann, K.; Mattis, R.; Conraths, F.J. Detection of Echinococcus multilocularis in foxes: Evaluation of a protocol of the intestinal scraping technique. J. Vet. Med. B. Infect. Dis. Vet. Public Health 2006, 53, 395-398. [CrossRef]

16. Umhang, G.; Woronoff-Rhen, N.; Combes, B.; Boue, F. Segmental sedimentation and counting technique (SSCT): An adaptable method for qualitative diagnosis of Echinococcus multilocularis in fox intestines. Exp. Parasitol. 2011, 128, 57-60. [CrossRef] [PubMed]

17. Eckert, J. Predictive values and quality control of techniques for the diagnosis of Echinococcus multilocularis in definitive hosts. Acta Trop. 2003, 85, 157-163. [CrossRef]

18. Conraths, F.J.; Deplazes, P. Echinococcus multilocularis: Epidemiology, surveillance and state-of-the-art diagnostics from a veterinary public health perspective. Vet. Parasitol. 2015, 213, 149-161. [CrossRef]

19. Duscher, G.; Prosl, H.; Joachim, A. Scraping or shaking-a comparison of methods for the quantitative determination of Echinococcus multilocularis in fox intestines. Parasitol. Res. 2005, 95, 40-42. [CrossRef]

20. Trachsel, D.; Deplazes, P.; Mathis, A. Identification of taeniid eggs in the faeces from carnivores based on multiplex PCR using targets in mitochondrial DNA. Parasitology 2007, 134, 911-920. [CrossRef]

21. Boubaker, G.; Macchiaroli, N.; Prada, L.; Cucher, M.A.; Rosenzvit, M.C.; Ziadinov, I.; Deplazes, P.; Saarma, U.; Babba, H.; Gottstein, B.; et al. A multiplex PCR for the simultaneous detection and genotyping of the Echinococcus granulosus complex. PLoS Negl. Trop. Dis. 2013, 7, e2017. [CrossRef] [PubMed]

22. Knapp, J.; Millon, L.; Mouzon, L.; Umhang, G.; Raoul, F.; Ali, Z.S.; Combes, B.; Comte, S.; Gbaguidi-Haore, H.; Grenouillet, F.; et al. Real time PCR to detect the environmental faecal contamination by Echinococcus multilocularis from red fox stools. Vet. Parasitol. 2014, 201, 40-47. [CrossRef] [PubMed]

23. Oines, O.; Isaksson, M.; Hagstrom, A.; Tavornpanich, S.; Davidson, R.K. Laboratory assessment of sensitive molecular tools for detection of low levels of Echinococcus multilocularis-eggs in fox (Vulpes vulpes) faeces. Parasit. Vectors 2014, 7, 246. [CrossRef] [PubMed]

24. Hoffmann, B.; Depner, K.; Schirrmeier, H.; Beer, M. A universal heterologous internal control system for duplex real-time RT-PCR assays used in a detection system for pestiviruses. J. Virol. Methods 2006, 136, 200-209. [CrossRef] [PubMed] 
25. Casulli, A. Recognising the substantial burden of neglected pandemics cystic and alveolar echinococcosis. Lancet Glob. Health 2020, 8, e470-e471. [CrossRef]

26. Budke, C.M.; Deplazes, P.; Torgerson, P.R. Global socioeconomic impact of cystic echinococcosis. Emerg. Infect. Dis. 2006, 12, 296-303. [CrossRef]

27. Wassermann, M.; Woldeyes, D.; Gerbi, B.M.; Ebi, D.; Zeyhle, E.; Mackenstedt, U.; Petros, B.; Tilahun, G.; Kern, P.; Romig, T. A novel zoonotic genotype related to Echinococcus granulosus sensu stricto from southern Ethiopia. Int. J. Parasitol. 2016, 46, 663-668. [CrossRef]

28. Lefever, S.; Pattyn, F.; Hellemans, J.; Vandesompele, J. Single-nucleotide polymorphisms and other mismatches reduce performance of quantitative PCR assays. Clin. Chem. 2013, 59, 1470-1480. [CrossRef]

29. Laurimae, T.; Kinkar, L.; Moks, E.; Romig, T.; Omer, R.A.; Casulli, A.; Umhang, G.; Bagrade, G.; Irshadullah, M.; Sharbatkhori, M.; et al. Molecular phylogeny based on six nuclear genes suggests that Echinococcus granulosus sensu lato genotypes G6/G7 and G8/G10 can be regarded as two distinct species. Parasitology 2018, 145, 1929-1937. [CrossRef]

30. Maksimov, P.; Schares, G.; Press, S.; Frohlich, A.; Basso, W.; Herzig, M.; Conraths, F.J. Comparison of different commercial DNA extraction kits and PCR protocols for the detection of Echinococcus multilocularis eggs in faecal samples from foxes. Vet. Parasitol. 2017, 237, 83-93. [CrossRef]

31. Garland, S.; Baker, A.; Phillott, A.D.; Skerratt, L.F. BSA reduces inhibition in a TaqMan assay for the detection of Batrachochytrium dendrobatidis. Dis. Aquat. Organ. 2010, 92, 113-116. [CrossRef] [PubMed]

32. Stieger, C.; Hegglin, D.; Schwarzenbach, G.; Mathis, A.; Deplazes, P. Spatial and temporal aspects of urban transmission of Echinococcus multilocularis. Parasitology 2002, 124, 631-640. [CrossRef] [PubMed]

33. Maksimov, P.; Isaksson, M.; Schares, G.; Romig, T.; Conraths, F.J. Validation of PCR-based protocols for the detection of Echinococcus multilocularis DNA in the final host using the Intestinal Scraping Technique as a reference. Food Waterborne Parasitol. 2019, 15, e00044. [CrossRef]

34. Svec, D.; Tichopad, A.; Novosadova, V.; Pfaffl, M.W.; Kubista, M. How good is a PCR efficiency estimate: Recommendations for precise and robust qPCR efficiency assessments. Biomol. Detect. Quantif. 2015, 3, 9-16. [CrossRef] [PubMed]

35. Scientific, T.F. DNA Copy Number and Dilution Calculator. Available online: https://www.thermofisher.com/ de/de/home/brands/thermo-scientific/molecular-biology/molecular-biology-learning-center/molecularbiology-resource-library/thermo-scientific-web-tools/dna-copy-number-calculator.html (accessed on 25 September 2020).

(C) 2020 by the authors. Licensee MDPI, Basel, Switzerland. This article is an open access article distributed under the terms and conditions of the Creative Commons Attribution (CC BY) license (http://creativecommons.org/licenses/by/4.0/). 